\title{
FORMAS DE SUJEIÇÃO E SOCIABILIDADE CAMPONESA NO SEMIÁRIDO
}

\author{
FORMS OF SUBJECTION AND SOCIABILITY IN RURAL COMMUNITIES \\ OF THE BRAZILIAN SEMI-ARID REGION
}

\author{
FORMAS DE SUJECCIÓN Y SOCIABILIDAD CAMPESINA \\ EN EL SEMIÁRIDO
}

\author{
Alexandra Maria de Oliveira - Universidade Federal do Ceará - Fortaleza - Ceará - Brasil \\ alexandra.oliveira@ufc.br
}

\section{Resumo}

As formas de sujeição e a sociabilidade do campesinato na sociedade capitalista estão no cerne do debate aberto neste artigo. Para isso, apresentam-se diferentes formas de sujeição do trabalho e de apropriação da renda da terra no semiárido. A análise tem por base a teoria social e discute a questão camponesa no interior do movimento contraditório de desenvolvimento do capitalismo. A pesquisa foi desenvolvida por meio de estudo transversal realizado em assentamentos rurais no Ceará no período de 2004 a 2008. Foi possível identificar que o campesinato, na conquista de frações do território capitalista, tem desenvolvido relações de trabalho e sociabilidade, utilizadas como estratégias de reprodução social, e que, cada vez mais, novas frentes de luta pela reforma agrária têm emergido com a participação política dos camponeses.

Palavras-chave: formas de sujeição, campesinato, região semiárida.

\begin{abstract}
The primary focus of the present paper is the forms of subjection and sociability presented by rural Brazilian communities in the context of capitalist society. For this, the study presents the different forms of labor oppression and the appropriation of income derived from rural activities found in the Brazilian semi-arid region. The analysis of these phenomena is based on social theory and the discussion of the question of rural social movements as a contradictory force to the development of capitalist society. This research was based on a transversal study of rural settlements in the Brazilian state of Ceará between 2004 and 2008. It was possible to confirm that the rural communities, in their efforts to conquest a portion of the capitalist territory, have developed relationships of work and sociability, based on a strategy of social reproduction, and that new fronts in the struggle for agrarian reform continue to emerge through the political efforts of the rural population. Key words: forms of subjection, rural communities, semi-arid region.
\end{abstract}

\section{Resumen}

Las formas de sujeción y la sociabilidad del campesino en la sociedad capitalista están en el centro del debate, abierto en este artículo. Para eso, se presentan diferentes formas de sujeción del trabajo y de apropiación de la renta de la tierra en el semiárido. El análisis se basa en la teoría social y discute la cuestión campesina al interior del movimiento contradictorio del desarrollo del capitalismo. La investigación fue desarrollada por medio del estudio transversal realizado en asentamientos rurales del Ceará en el periodo de 2004 a 2008 . Fue posible identificar que el campesinado, en la conquista de fracciones de territorio capitalista, ha desarrollado relaciones de trabajo y sociabilidad, utilizadas como estrategias de reproducción social, y que, cada vez más, nuevas frentes de lucha por la reforma agraria han emergido con la participación política de los campesinos.

Palabras clave: formas de sujeción, campesinado, región semiárida. 
Introdução

A análise sobre formas de sujeição e sociabilidade camponesa no semiárido cearense abre espaços para discussões acerca da política de desenvolvimento presente no campo brasileiro e seus desdobramentos. A subordinação da renda da terra ao capital recoloca a questão da reforma agrária e do acesso à terra pelos sem-terra, e o problema da estrutura fundiária e da reprodução do campesinato na sociedade moderna.

A reflexão proposta passa pela leitura presente nas ciências humanas sobre o processo de desenvolvimento do modo capitalista de produção no território brasileiro. Um processo contraditório e combinado, pois, à medida que avança, reproduzindo relações especificamente capitalistas caracterizadas pela apropriação privada da terra, cria e recria, igual e contraditoriamente, relações camponesas de produção mantidas com base no trabalho familiar.

A política pública priorizada foi a reforma agrária de mercado do Banco Mundial, que teve como vetor inicial, no Brasil, a experiência ocorrida no estado do Ceará, através do programa reforma agrária solidária (1996-1997). A política teve como pressuposto a criação de um fundo de terras para financiar a compra e a venda de terras entre proprietários dispostos a vendê-las e camponeses sem-terra interessados em adquirir terra para trabalhar.

A reforma agrária de mercado foi resultado, ainda, da pressão política de movimentos socioterritoriais e representações camponesas na luta pela reforma agrária durante a segunda metade dos anos noventa, no governo Fernando Henrique Cardoso (1995-2002). A resposta do Estado veio com ações de governo que sinalizaram a direção da implantação de uma política de desenvolvimento rural em consonância com a elite agrária. Nesse sentido, a reforma agrária de mercado, entendida como uma política de contrarreforma agrária aparece como condição e consequência da forma pela qual o Estado foi levado a recriar o mercado de terras para favorecer o desenvolvimento do capitalismo no país.

Esta pesquisa foi desenvolvida por meio de estudo transversal realizado em oito assentamentos rurais criados no decorrer do programa de reforma agrária de mercado no Ceará. A seleção dos assentamentos levou em consideração as áreas prioritárias para a instalação dos primeiros assentamentos - os municípios de Acaraú e Canindé. Os assentamentos Almécegas (1997), Ana Veríssimo (1997), Campos do Jordão (1998), Cauassu 
(1997), Feijão (1998), Juá (1998), Santa Rita (1997) e São Felipe (1998) abrigam famílias originárias de grupos de camponeses sem-terra das regiões do litoral oeste e do sertão central cearense.

O objetivo do artigo é apresentar diferentes formas de sujeição da renda da terra ao capital e a sociabilidade camponesa desenvolvida como estratégia de reprodução social. Para isso, o texto foi dividido em momentos distintos: no primeiro momento, revelam-se as origens do campesinato estudado e as formas de sujeição da renda ao capital; no segundo, adentra-se na organização territorial camponesa revelando as vilas e os assentamentos rurais como territórios de sociabilidade camponesa; no terceiro, são apresentadas as considerações finais, que apontam para a importância do campesinato no processo de desenvolvimento da sociedade moderna.

\section{Formas de sujeição camponesa}

Os camponeses dos assentamentos Almécegas, Ana Veríssimo, Campos do Jordão, Cauassu, Feijão, Juá, Santa Rita e São Felipe apresentaram diferentes formas de sujeição da renda da terra ao capital. Essas relações estão intimamente vinculadas ao domínio da apropriação privada da terra presente na agricultura brasileira.

As histórias de vida dos camponeses estão compostas por relações sociais de trabalho e produção que se revelaram nas figuras do morador de condição (parceiros e/ou rendeiros), do patrão ou fazendeiro, do morador de vila ou diarista e, ainda, de camponeses migrantes temporários, que, após a proletarização nos centros urbanos, retornaram ao campo em busca de terra para trabalhar.

Andrade (1986), ao analisar o trabalho escravo e o tráfico negreiro ocorridos no Nordeste da primeira metade do século XIX, identificou que a figura do "morador de condição" surgiu nas estreitas relações presentes nos engenhos de cana-de-açúcar na zona da mata nordestina, como uma estratégia dos fazendeiros para manter por perto mão de obra para o trabalho com a cultura, mas assumiu também importância nas fazendas de gado e na cultura do algodão no sertão. Assim, a economia sertaneja, que se iniciou basicamente com a criação de gado, tinha na lavoura do algodão sua maior dinamização e um elemento fixador da população no campo.

Para Silva (1995), a colonização do Ceará se deu a partir das grandes fazendas de gado. Somente após meados do século XVIII, o algodão en- 
trou em cena, favorecendo as bases para uma nova organização do espaço, pautada na relação gado e algodão. A produção do algodão como produto comercial foi deixada aos cuidados de fazendeiros, sitiantes e parceiros. O grande fazendeiro criador de gado permitia a permanência de meeiros e posseiros na propriedade, plantando o algodão. Assim, foi possível certa acumulação de bens pelos camponeses, embora seu trabalho estivesse subordinado ao patrão. O pagamento da renda da terra poderia acontecer de diversas maneiras: em dias de serviço, em produtos ou, ainda, em dinheiro.

Conforme Sá Jr. (1976), na formação da economia nordestina as atividades comerciais obtiveram sempre as melhores terras, o que favoreceu um processo de concentração de renda e propriedade que resultou na marginalização das atividades de subsistência. A utilização das unidades de subsistência que funcionavam dentro das próprias unidades produtivas voltadas para exportação era condicionada ao pagamento da renda. Desse modo, nos anos de 1950 e 1960, a expansão de grandes propriedades tornava-se compatível com os pequenos estabelecimentos que, dentro ou às vezes fora delas, se desenvolviam e tinham por base relações não capitalistas.

Ao analisar as diferentes formas de renda da terra pré (não)-capitalistas, Oliveira (1986, p. 80) lembrou que "elas aparecem adquirindo formas novas que o próprio capital engendra de modo a manter seu domínio no campo". Dessa forma, o autor as concebeu, como produto excedente, que aparece sob formas distintas: como renda em trabalho, renda em produto e renda em dinheiro. Portanto, a expressão pré-capitalista deve-se à sua origem histórica anterior ao capitalismo. Mas isso não quer dizer que essas formas de renda não possam aparecer no capitalismo.

Dentre as diferentes formas da renda da terra pré-capitalista, a renda em trabalho seria a mais simples, "pois os produtores, [...] trabalham as terras de outrem, muitas vezes coercitivamente, recebendo em troca apenas o direito de lavrar parte dessas terras para si próprio" (Oliveira, 1986, p. 80).

Nos relatos dos agricultores camponeses sobre o que faziam antes de participarem dos assentamentos (suas origens), são citadas diferentes formas de sujeição do trabalho camponês ao capital personificado na figura do patrão, entre as quais está a sujeição da renda da terra em trabalho. 
Eu mesmo trabalhava com a renda aqui na fazenda. Quando a gente começou a trabalhar aqui, a gente não tinha como ganhar nada. Aí a gente falou com o proprietário. E ele disse que o terreno dele não poderia ser utilizado para plantar, porque ele criava muito e queria forragem. Mas arrendava as matas para a gente tirar a madeira. A gente dando em troca o roçado feito, queimado no tronco, para ele semear a forragem para os bichos dele. Nós dando a terra preparada para ele plantar, fazer forragem. Então, a gente pegou a desmatação de 1993 até 1997. Nesse período, estivemos trabalhando aqui, para o proprietário. A gente tinha direito só a lenha, madeira de obra [tronco da carnaúba] ele não deixava tirar, e não era toda madeira que ele deixava cortar. Trabalhamos praticamente aqui quatro anos. Com cinco anos foi que ele cortou o serviço dizendo que queria vender a terra. A gente não morava aqui, só trabalhava como rendeiro. A gente estava ganhando só o sustento mesmo e dando outra parte, que era a terra preparada. (Sr. A., Assentamento Santa Rita, 2002)

No caso acima, o pagamento da renda da terra ocorreu quando o rendeiro - produtor direto -, com os instrumentos de trabalho que lhe pertenciam de fato, durante alguns anos, cultivou as terras do proprietário, recebendo em troca o direito de retirar madeira em tora para si próprio. Dessa forma, o camponês rendeiro deu gratuitamente anos de lida ao patrão, entregando-lhe o terreno preparado.

Outra forma simples de relação social característica de sujeição camponesa foi o pagamento da renda da terra em produtos. Segundo Oliveira (1986, p.81), "a renda em produto tem origem quando o trabalhador cede parte de sua produção ao proprietário da terra, pelo fato deste (o proprietário) ter cedido o direito para que ele cultivasse a terra”.

Os depoimentos camponeses que seguem apontam para essa outra forma de sujeição da renda da terra.

Eu pagava renda, pagava três dias na semana. A gente pagava renda, o algodão era de meia, se desse dez arrobas cinco era meu e cinco do patrão. Aí se a gente desse os dias de serviço, o milho e o feijão era da gente. E se a gente não desse os dias de serviço, a gente dava, também, um bocadinho do milho. E era assim, três dias da semana para o dono da terra. O algodão era de metade e os legumes (milho e feijão) de três um. (Sr. A., Assentamento Juá, 2001)

O depoimento do parceiro revelou esse tipo de sujeição clássica da renda da terra ao capital - a renda em produtos. Outra característica marcante nessa forma de renda é a coerção, muitas vezes substituída pelo direito expresso com contratos verbais. No caso relatado, o parceiro cedeu 
parte de sua produção ao proprietário da terra, pelo fato de o dono ter cedido o direito para que o camponês trabalhasse e morasse na terra.

No caso a seguir, a subordinação do trabalho esteve ligada à necessidade de terra para trabalhar.

Nós morávamos aqui nessa vila [vila dos Caúlas] trabalhando avulso. Nós trabalhávamos aqui nessa fazenda com pagamento de renda, de cinco um. (Sr. M., Assentamento Feijão, 2003)

Na fala, o camponês revelou outra forma diferente de pagamento da renda em produtos - a quinta, o que quer dizer que a cada cinco sacas de algodão, por exemplo, uma ficava com o patrão.

De acordo com Oliveira (1986, p. 82), “a renda em produtos, também conhecida como parceria, adquire regionalmente, no Brasil, diferentes formas. Dentre as mais conhecidas temos a meação, a terça e a quarta [...]”. No caso específico estudado, foi possível observar a parceria em forma de meia, de terça e de quinta.

Portanto, o que os camponeses rendeiros e parceiros revelaram foi, antes de tudo, a sujeição da renda da terra ao capital. $\mathrm{O}$ fato de não ter a propriedade da terra ou não ter onde morar e trabalhar fez com que esses camponeses durante anos tivessem que pagar renda aos proprietários de terra. Dito de outro modo, a propriedade privada da terra é o motivo fundante da geração e do pagamento de rendas.

As rendas de origem pré (não)-capitalistas se transformam em renda capitalizada da terra a partir do entendimento de que a sociedade camponesa é parte constitutiva da sociedade capitalista moderna. Assim, a renda da terra é parte fundante do processo de produção do capital na sociedade capitalista.

Para Martins (1981), o capitalismo, em seu desenvolvimento, não só redefine antigas relações, subordinando-as à reprodução do capital, mas também engendra relações não capitalistas igual e contraditoriamente necessárias a essa reprodução. Nesse contexto, não é possível concordar com a tese que afirma ser o campesinato um empecilho ao desenvolvimento do capitalismo no campo brasileiro.

Segundo Oliveira (2005), do ponto de vista da acumulação do dinheiro, o processo ocorre através de uma relação de troca pautada na lógica da dependência. Assim, de um lado há proprietários de terra que têm por base a extração da renda da terra, com o claro objetivo de transformá- 
-la em capital, portanto, de gerar o lucro. Do outro lado, há uma sociedade que tem como premissa o sustento da família, e não a acumulação. Nessa troca de favores, questões como cativeiro, sujeição, violência e expropriação aparecem na base do desenvolvimento do modo de produção capitalista no campo.

O dinheiro acumulado entre os proprietários de terra dependia da produção que os moradores de suas fazendas realizassem. Então, quanto mais trabalhadores "sujeitos" trabalhassem numa dada fazenda, melhor para o fazendeiro, que assumia e assume, muitas vezes, o duplo papel de proprietário de terra rentista e capitalista.

Uma família camponesa explicou o cativeiro, a sujeição e a exploração do trabalho camponês a partir da relação desigual entre patrão e morador.

Porque a gente era obrigado a dar três dias por semana ao patrão e, ainda, repartia o legume. O dia que a gente não ia trabalhar, ele achava ruim. Ameaçava de botar para fora, botava os animais para comer o legume da gente. A gente não tinha direito nem a forragem, nem a nada. Esse [patrão], ainda, era um dos patrões bom que, ainda, dava uma rês para você tirar o leite e dava a forragem para você tirar do capim dele. Certo que você estava tratando do gado dele, mas, estava se lucrando do leite. Ele não era muito ruim, não. Mas, tinha outros mais cativeiro, que castigava mesmo [sic]. Você tinha que dar os três dias, se você não desse era expulso do imóvel. Ia embora para outra fazenda. (Sr. A., Assentamento Juá, 2002)

O cativeiro aparece como o cerceamento da liberdade do trabalhador. A condição de ser cativo é oposta à de ser livre; é estar subordinado, numa situação de exploração. $\mathrm{O}$ trabalho no cativeiro sempre implica uma subordinação, uma exploração que define um estado de servidão. No depoimento, aparece a construção da consciência e da crítica ao patrão.

Assim como a situação de cativeiro da terra analisada por Martins (1981), encontramos no semiárido o cativeiro do camponês, da vida de se sentir como escravo, de se sentir extremamente oprimido. A lembrança pode ser, ainda, referência a uma possível alusão ao trabalho escravo na terra. Desse modo, a propriedade privada da terra instituiu uma forma de cativeiro, o cativeiro da terra.

Depois que a gente começou a comprar os imóveis foi que o patrão começou a ficar só, foi e quebrou. Porque o patrão tinha trinta morador [sic], então ele tinha trinta filho trabalhando para ele, produ- 
zindo para ele. Quer dizer que ele pagava a diária do preço que ele queria, do jeito que ele queria. Todos os trinta plantavam e cada um deixava lá dentro do roçado de três carreiras ele [o patrão] tinha direito a uma. Se fosse [sic] cem carreiras, eu tirava minha parte e o restante era dele. Aí ele recebia de graça sem ter um 'pingo' de trabalho. Ele cansou de bater trezentos, quinhentos e até mil sacas de milho sem mover uma palha. E nós recebia [sic] o algodão de três um, às vezes era de metade, aí quer dizer que ele crescia, porque tinha um bando de filho trabalhando, quando isso se acabou, aí ele morreu. Não teve mais a família para trabalhar para ele. Ele ficou só, uma pessoa morta. Ele não tinha mais como se manter. Quer dizer que ele pagava aquelas diárias de serviço, do preço que ele queria, do jeito que ele queria. Quer dizer que aquelas pessoas [os moradores] viviam naquele cativo. O tipo cativeiro. Aí, agora ele mora bem acolá, se ele quiser um dia de serviço nosso, nós vamos trabalhar do preço que nós quisermos. Se ele disser: 'é tanto'. A gente diz: 'não, só vou por tanto'. E só vai se quiser que a gente não é obrigado a ir. E na época que nós morávamos com ele, ele dizia: 'você amanhã vai me dar um dia de serviço e eu só pago três reais'. E eu era obrigado a ir e ganhar os três reais, porque eu morava com ele. Se eu não fosse, ele dizia: 'pois, amanhã desocupe a minha casa' e eu tinha que desocupar. Aí quando nós 'compramos' o imóvel acabou-se isso. Agora se ele disser assim: 'amanhã você vai me dar um dia de serviço'. Aí eu digo: 'eu não vou!' E quero vê se ele obriga a ir! Obriga não, que eu não devo nada a ele. (Sr. F., Assentamento Juá, 2002)

No depoimento, a lógica da dependência pautada na troca de favores apareceu como razão do enriquecimento do patrão, que tinha nos moradores, considerados pessoas da família, a força de trabalho geradora de renda na fazenda. A conquista de uma fração do território com o assentamento levou ao esvaziamento da fazenda e, com isso, ao empobrecimento do patrão, e, aos camponeses, a conquista da autonomia e da liberdade de trabalho.

O cativeiro e a sujeição indicam pistas importantes para a compreensão da escolha do caminho seguido pelos agricultores camponeses estudados. E a consciência de classe construída na experiência tem sido de fundamental importância para garantir a reprodução camponesa nos assentamentos rurais do semiárido cearense.

Nos assentamentos Almécegas, Ana Veríssimo, Campos do Jordão, Cauassu, Feijão, Juá, Santa Rita e São Felipe apareceram, também, casos de camponeses sem-terra que, sem condições de permanecer no campo, migraram temporariamente em busca de trabalho e encontraram a proletarização nas cidades. Como proletário assalariado ou trabalhador infor- 
mal, o trabalhador, com sua trajetória de vida, pode não estar camponês, apesar de sê-lo.

Ao comentar sobre o que faziam antes do assentamento, os camponeses revelaram quadros de pobreza, expropriação, migração temporária e retorno, como veremos nos relatos a seguir.

Eu morava no Jatobá e trabalhava na terra do finado Pompeu Sampaio. Nessa época eu morava com minha família. Quando meu pai faleceu viemos para o Canindé, e no Canindé trabalhei de camelô na Igreja, vendia aquelas bijuterias: cordão, fita, santinho, chaveiro. Eu também era diarista de limpa de mato, diarista-servente. Aí foi quando eu conheci o Evandro; ele estava formando essa associação e eu recebi o convite. Meu sonho era viver no campo, era o que eu sabia mais fazer mesmo. (Sr. G., Assentamento Santa Rita, 2002)

No caso relatado, o morador de condição foi expulso com a família para a cidade, proletarizando-se no trabalho informal como camelô, mas mantendo relação com o campo, via trabalho assalariado temporário, com recebimento de diárias. O assentamento apareceu como a realização do sonho de vida. Para outro camponês, o caminho foi o da migração.

Eu nasci no município de Cruz, meu pai era agricultor. Fiquei com ele até os dezesseis anos. Em 1975 fui embora para Brasília arriscar a vida. Saí da minha terra como peão e vivi como peão na até 1998. Hoje, se me tirar da minha enxada, da minha foice, do meu machado, da minha galinha, da minha vaca, da minha cabra, da minha porca e meu pé de roça, pode pegar e me matar. Eu nasci para ser da roça, eu gosto é da roça. (Sr. V., Assentamento Cauassu, 2002)

No depoimento descrito, um jovem camponês migrou temporariamente para a cidade grande, proletarizando-se como trabalhador da construção civil. Após um tempo retornou à terra natal, e o assentamento apareceu como a possibilidade de retomar o trabalho no campo.

Nos depoimentos já apresentados anteriormente se observou o processo de expropriação e exploração do trabalho camponês. Na cidade, esse trabalhador vive situações também complexas. Ele se proletariza ora parcialmente (mantendo vínculos com o campo) ora integralmente (rompendo com o campo). Porém, de todo modo, foi possível perceber que esse trabalhador pode ter sua história de vida, sua identidade camponesa, mas em um determinado momento não está se realizando enquanto camponês. 
Relações de trabalho e sociabilidade no semiárido

Os agricultores, integrantes dos assentamentos, podem ser agrupados em três categorias, conforme suas histórias de vida e as relações sociais de trabalho e produção desenvolvidas com o patrão: a) camponeses rendeiros; b) camponeses parceiros; c) camponeses migrantes temporários.

Os rendeiros, em sua maioria, pagavam a renda em trabalho. Não residiam na propriedade onde trabalhavam e viviam nas pequenas vilas, comumente conhecidas como vilas rurais, que se estendem ao longo das estradas. Os parceiros constituem a maioria. Moravam na propriedade onde trabalhavam, pagando renda em produtos via formas de parceria e subjugando-se ao recebimento de diárias com o valor estabelecido pelo patrão. Os migrantes temporários, por sua vez, moravam nas cidades e vilas, às vezes trabalhavam nas fazendas como diaristas e, em sua quase totalidade, passaram pelo processo de proletarização urbana.

A exemplo da origem dos camponeses estudados por Alencar (2002) e Moura (2003), nos assentamentos pesquisados, camponeses rendeiros, parceiros e migrantes temporários formam os três grupos de sem-terra que integram os assentamentos rurais adquiridos a partir da compra de terra via programa de reforma agrária de mercado do Banco Mundial no Ceará.

De uma maneira geral, os relatos são entremeados de especificidades, mas expressam uma mesma voz. A voz de um campesinato, que, para Martins (1995, p. 16), “quer entrar na terra, [...]”. É uma classe formada por sujeitos sociais que se diferenciam na origem, mas que trazem em suas raízes a identidade e a condição camponesa.

Os camponeses assentados são originados de três grandes grupos de sem-terra que se reuniram no final da década de 1990, para sair do cativeiro e adquirir a posse da terra. Assim como os camponeses dos Assentamentos Batalha e Mata Fresca, discutidos por Moura (2003), a maioria dos assentados é proveniente dos municípios onde se formaram os assentamentos, e entre eles os vínculos de origem se confundem, muitas vezes, com o de parentesco. Esse parentesco deve ser entendido num sentido amplo, para além da descendência familiar, conforme Moura (1978, p. 32). Portanto, significa dizer que “a palavra 'parente' serve para identificá-los num todo, em que todos estão unidos, [...]. Significa dizer que as pessoas atuam como parentes". 
Aqui o que mais tem é compadres uns dos outros. É porque é padrinho dos meninos. Eu sou compadre de quase todos, por causa de apelido. É coisa entre nós mesmos. (Sr. J., Assentamento Juá, 2002)

Em todos os assentamentos há parentes e compadres, que, além de descendentes, são camponeses sem-terra que possuem laços familiares fortalecidos com casamentos, apadrinhamentos, heranças e vizinhanças.

Woortmann (1995, p. 247), ao fazer o estudo comparativo da família camponesa no Sul e no Nordeste e sua importância como instituição que preserva valores culturais, endossa essas ideias, ao considerar que "a linguagem de parentesco joga um papel de esquema organizador, não apenas no seio do discurso desses camponeses, mas também em sua prática”.

A linguagem de parentesco teve um papel organizador na seleção das famílias, e que, ainda, essa linguagem deve ser vista como parte constitutiva de uma sociabilidade do grupo (Candido, 2001, p. 87). Longe de ser uma relação harmoniosa, a linguagem de parentesco pode se tratar de uma relação conflituosa, cheia de percalços. A solidariedade, o compadrio, as relações de vizinhança presentes na unidade territorial e social estão atravessadas por uma série de sentimentos que se contrapõem no movimento cotidiano dos assentados.

É preciso lembrar que a sociabilidade camponesa, envolve outras relações como a vizinhança, a religiosidade e o compadrio, entre outras. Nesta pesquisa, foi enfatizada a relevância da sociabilidade camponesa para as práticas de ajuda mútua e do trabalho coletivo, ações relativas à luta pela posse e uso da terra e pela liberdade no trabalho.

A linguagem de parentesco, enquanto parte da sociabilidade presente na organização do grupo, se substantivou nas constantes vilas presentes na área rural. Desse modo, consideramos que as unidades territoriais de origem dos camponeses foram importantes no processo de organização das famílias assentadas.

Marques (1994, p. 50-51), ao estudar o modo de vida camponês nos sertões da Paraíba, apontou para o fato de que "agora esvaziada, a fazenda não é mais a principal unidade de sociabilidade. Grupos de vizinhança, povoados e cidades tornam-se os principais centros da vida social sertaneja”.

Para a autora, a importância da fazenda para o estudo da sociabilidade camponesa no sertão está arrefecida. Não é que os camponeses não tenham mais vínculos com a fazenda, mas para entender a comunidade 
camponesa, o que era antigamente fundamental, ou seja, passar por dentro da fazenda, não o é mais. Agora, é preciso ir, também, buscar entender o campesinato nas comunidades que estão fora das fazendas, ou seja, nos assentamentos, nas vilas rurais, nos povoados ou nos bairros rurais. Para Oliveira (2010, 2013), escolas do campo gestadas por representações camponesas como o Movimento dos Trabalhadores Rurais (MST) e a Comissão Pastoral da Terra (CPT) estão caminhando no sentido de construir leituras das comunidades camponesas e suas organizações territoriais.

No Ceará, as fazendas, mesmo tendendo ao esvaziamento, são unidades sociais e territoriais elementares para se estudar o sertão. Porém a principal unidade territorial e social que se revelou como originária dos camponeses assentados foram as vilas rurais, as quais aparecem como lugares de negação do cativeiro e da sujeição imposta pelo fazendeiro. Embora o morador de vila se considere um trabalhador liberto, a pobreza de não ter onde trabalhar o sujeita às diárias oferecidas pelo patrão. Assim, a sujeição ocorrida fora da fazenda se difere daquela ocorrida dentro dela, contudo o morador de vila aparece tão sujeitado quanto o morador de sujeição da fazenda.

A sujeição camponesa dentro da fazenda indica uma relação do camponês com o fazendeiro, a qual passa pela lógica da dependência, da troca de favores, da dívida moral. Quando o camponês está fora, não está totalmente livre desse tipo de relação porque a lógica da dominação permeia as relações sociais no sertão de uma maneira geral. Coronel é coronel, dentro ou fora da fazenda. Mas, de toda forma, a saída do camponês da fazenda relativizou e diminuiu o poder do coronel.

Nos assentamentos pesquisados, as origens camponesas se encontram em unidades territoriais distintas: fazendas, vilas rurais e cidades pequenas. Como já dissemos, a maioria das famílias assentadas é oriunda de vilas presentes na área rural. A outra parte das famílias é proveniente das fazendas e cidades próximas, com distância máxima de quarenta quilômetros.

As relações de sociabilidade construídas cotidianamente no interior dessas vilas foram fundamentais na organização dos grupos e na seleção das pessoas a serem assentadas. Descendência, afinidade, amizade, trabalho com a terra, foram relações que pesaram na escolha das famílias. Mas, considerando que era preciso arcar com o pagamento da terra, foram convidadas “pessoas responsáveis, direitas e trabalhadoras”. 
A formação das vilas rurais está atrelada à situação de proletarização transitória vivenciada pelos camponeses, que, negando o cativeiro, pousam nas vilas, as quais assim tornam-se lugares de rearticulação da vida no campo.

Algumas dessas vilas se formaram com a decadência da pecuária no sertão, levando à redução do número de moradores nas fazendas. O fazendeiro passou, então, a vender ou doar pequenos lotes de sua fazenda aos moradores, como foi o caso da vila Boa Vista dos Caúlas ou vila dos Caúlas, localizada no povoado dos Caiçaras, estrada CE-257, entre os municípios de Canindé e Santa Quitéria.

De acordo com o grupo do Assentamento Feijão, a vila dos Caúlas é antiga. "O fazendeiro vendeu pequenos lotes da fazenda para o pessoal fazer as casas. Primeiro, fizeram duas casas na beira da estrada e o pessoal foi fazendo as casas vizinhas. Eles são trabalhadores avulsos” (Grupo Assentamento Feijão, 2001).

Os moradores das vilas rurais, na maioria, são camponeses rendeiros ou diaristas, que trabalham nas fazendas próximas. Para poder ter moradia, eles pagam, durante dias, meses ou anos, renda da terra ao fazendeiro que lhes vendeu o chão da casa.

No caso das famílias do Assentamento Feijão, conforme o camponês,

Todos os moradores daqui, todos eram da vila dos Caúlas. Trabalhávamos mais para doutor Barros dos Santos. Mas não tinha fazenda certa, não. Trabalhávamos onde desse certo, como diarista. No inverno, nós plantava e pagava [sic] de cinco uma. No "verão", ele nos arrendava a olaria e nós passávamos o "verão" fazendo tijolos, pagando renda de cinco um. Hoje não pagamos mais renda. (Sr. N., Assentamento Feijão, 2001)

A possibilidade do fim do cativeiro levou muitos moradores de sujeição a procurar abrigo nas vilas, na busca da liberdade. Lá, o crescimento do número de moradores leva a crer que "hoje poucas são as pessoas que moram em fazenda, moram mais em assentamentos, ou vila, para ficar liberto, trabalhando por aqui e por acolá. Só que não é bom, porque de qualquer maneira a gente paga renda” (Sr. R., Assentamento Feijão, 2002).

A vila do Cauassu se localiza na Estrada Velha, entre os municípios de Acaraú e Itarema. Nasceu com a estrada do Curral Velho, por volta dos anos de 1940. É uma vila extensa, que cresceu com o casamento dos filhos dos antigos moradores, que, às vezes, vão embora, mas voltam. Outras 
vezes se arrumam em um pequeno terreno, encostado à casa de parentes. Nem todos têm sítio, só mesmo o espaço da casa. "A vila é formada por agricultores que se criaram dentro do campo. O mar é para ir buscar só o alimento" (Sr. I. Vila do Cauassu, 2003).

O Cauassu é uma vila rural onde há trabalhadores sertanejos e praianos ou "trabalhadores do seco e do molhado", como costumam falar no lugar. A proximidade com o mar favorece a flexibilidade no trabalho com a lavoura e a pesca, embora, no assentamento, a primeira atividade seja muito mais desenvolvida que a segunda.

A carcinicultura empresarial implementada no final dos anos noventa no litoral cearense dinamizou o espaço da vila do Cauassu. Por um lado, quase todos os moradores passaram a trabalhar nas empresas de camarão, e, por outro lado, os caminhos de travessia que davam acesso para o mar foram interditados pelas empresas de camarão. E, hoje, quase não existe mais saída para o mar. De acordo com uma moradora, "é tudo cheio de portões, os vigias, é todo mundo armado. Os ricos invadiram tudo. $\mathrm{O}$ Ibama proíbe a gente de pegar camarão para comer e não proíbe os ricos de cortar o mangue” (D. M., Vila do Cauassu, 2003).

O depoimento da moradora reflete, um pouco, sobre o que está sendo a ambivalência do capital industrial/comercial, que se instalou no litoral e vai criando a esperança dos subempregos, ao mesmo tempo, que impõe medo e revolta no cotidiano dos moradores das vilas camponesas no litoral cearense.

A vila da Japuara foi formada a partir da doação de terras de parceleiros para filhos agregados do Assentamento Japuara. Foi o primeiro assentamento rural do Ceará, desapropriado para cinquenta e nove famílias a partir da luta pela terra no ano de 1971. Localiza-se na BR-020, entre os municípios de Canindé e Quixadá.

No início, a vila era composta por cinco famílias. Depois, os filhos se casaram e vieram os netos, os sobrinhos, e foi aumentando a parentela. Cada família foi cedendo parte do seu terreno para o parente fazer a própria casa. Com o passar dos anos, alguns filhos de parceleiros foram para a cidade e venderam suas casas para outros moradores.

Toda a vila da Japuara é delimitada por uma cerca de madeira e arame que contorna as casas e divide os espaços de moradia. De acordo com os moradores, muita gente cerca a casa com madeira para evitar a entrada de animais doentes. "A cerca serve para dividir uma casa da outra, para formar o quintal. Porque se você quiser criar um porco ou outro 
animal, tem que ser cercado" (Sr. B., Vila Japuara, 2003). Na vila há uma forte presença das cercas de proteção ao redor das casas.

Nesse contexto, há vilas oriundas de fazendas, vilas que surgem ao longo das estradas e vilas que emergem no interior dos assentamentos rurais. As fazendas, as vilas e os assentamentos formam, portanto, unidades territoriais e de sociabilidade camponesa relevantes no sertão cearense.

\section{Considerações finais}

A realidade do campesinato cearense se apresenta como parte constitutiva do processo de desenvolvimento do modo capitalista de produção no território brasileiro. Assim, o modelo de desenvolvimento atual tem resultado, por um lado, na ampliação das relações especificamente capitalistas no campo, como a compra e a venda de terras. Por outro lado, os assentamentos conquistados na luta pela terra representam trunfos da não-sujeição, da não-expropriação da renda da terra pelo patrão, e da continuidade das relações camponesas no campo, tais como o trabalho individual (familiar), a ajuda mútua e o trabalho coletivo.

A acumulação de capital pelos grandes proprietários era mobilizada principalmente pela força de trabalho dos agricultores sem-terra, cuja reprodução esteve estreitamente vinculada às relações de parceria. Nesse sistema, parte da produção camponesa era destinada ao proprietário da terra como forma de pagamento pelo uso da terra. Através da parceria, os proprietários de terras recriavam modalidades de apropriação do trabalho excedente dos camponeses e acumulavam riquezas.

No processo de luta pela terra travada pelos camponeses organizados no campo brasileiro, as vilas e os assentamentos rurais correspondem a conquistas de frações do território capitalista. No cotidiano da vida de assentado, a relação com a terra, o trabalho familiar, as relações de parentesco e ajuda mútua são partes constitutivas de uma sociabilidade camponesa que identifica e unifica os sujeitos sociais que estão na luta pela terra no semiárido cearense.

A situação apresentada indica uma posição política na qual os camponeses se identificam como participantes de uma condição social em que seus interesses particulares, diante da sociedade moderna, passam a ser definidos como interesses específicos da classe envolvida no processo de luta pela terra e pela reforma agrária. 
Nessa perspectiva, um conjunto maior de camponeses passa a eleger movimentos socioterritoriais e representações camponesas como mediadores de seus interesses específicos. O desenrolar desse processo tem indicado a presença de novas frentes de luta pela terra e pela reforma agrária com a participação política dos camponeses na sociedade capitalista.

\section{Referências}

ALENCAR, F. A. G. O programa cédula da terra: o caso do Ceará. Fortaleza: ABRA, CPT, APR, Fian - Brasil, [s.n.] 2002.

ANDRADE, M. C. A terra e o homem no Nordeste. São Paulo: Atlas, 1986.

CANDIDO, A. Os parceiros do rio Bonito: estudo sobre o caipira paulista e a transformação dos seus meios de vida. São Paulo: Duas cidades/Editora 34, 2001.

MARQUES, M. I. M. O modo de vida camponês sertanejo e sua territorialidade no tempo das grandes fazendas e nos dias de hoje em Ribeira-PB. Dissertação (Mestrado em Geografia) - FFLCH/USP, São Paulo, 1994.

MARTINS, J. S. O cativeiro da terra. São Paulo: LECH, 1981.

. Os camponeses e a política no Brasil. Petrópolis, RJ: Vozes, 1995.

MOURA, A. M. P. "A porteira está aberta”: o programa de reforma agrária solidária - Cédula da Terra no Estado do Ceará. Dissertação (Mestrado em Geografia) NPGEO/ UFS, São Cristovam, 2003.

MOURA, M. M. Os herdeiros da terra. São Paulo: Hucitec, 1978.

SÁ JR., F. O desenvolvimento da agricultura nordestina e a função das atividades de subsistência. Estudos Cebrap III. São Paulo: Brasiliense, 1976.

SILVA, J. B. O algodão na organização do Espaço. In: SOUZA, S. (Coord.). História do Ceará. Fortaleza: Fundação Demócrito Rocha, 1995. p.23-35.

OLIVEIRA, A. M. A contrarreforma agrária do Banco Mundial e os camponeses no Ceará - Brasil. Tese (Doutorado em Geografia) - FFLCH, Universidade de São Paulo, São Paulo, 2005.

. Construindo saberes e conhecimentos geográficos com professores em serviço nas escolas do campo. Boletim Goiano de Geografia, Goiânia, v. 30, n. 2, p. 99-111, jul./dez., 2010.

. A escola camponesa na alternância e o ensino de Geografia. Mercator: Revista de Geografia da UFC, Fortaleza, v. 12, n. 27, p. 171-187, jan./abr., 2013.

OLIVEIRA, A. U. Renda da terra pré-capitalista. Revista Orientação, São Paulo, IG/USP, n. 7, p. 77-86, 1986.

WOORTMANN, E. F. Herdeiros, parentes e compadres: São Paulo; Brasília: Hucitec/Edunb, 1995. 
Alexandra Maria de Oliveira - Possui Licenciatura e Bacharelado em Geografia pela Universidade Federal do Ceará. Mestrado em Geografia pela Universidade Federal de Sergipe e Doutorado em Geografia Humana pela Universidade de São Paulo. Atualmente é professora na Universidade Federal do Ceará.

Recebido para publicação em 26 de março de 2015

Aceito para publicação em 12 de maio de 2015 